\title{
Narrativa de Fanfiction: o autor e o leitor (des) autorizados pela cibercultura
}

\author{
Verônica Alves dos Santos Conceição (UEFS/UNIT) \\ Cristiane de Magalhães Porto (UNIT/ITP) \\ Isabella Silva dos Santos (UNIT)
}

\section{Resumo}

O estudo, inspirado nos pressupostos da Cibercultura, aborda o processo de autorizar-se enquanto autor e leitor de fanfiction. Trata das práticas de escrita e leitura de fanfiction para, como desdobramento, discutir o deslocamento do lugar do autor e do leitor de um texto em um contexto de Cibercultura. Para tanto, entabula- se uma conversa com autores como Chartier (1999, 2001, 2002), Jenkins (2009, 2015), Marcuschi (2008, 2010), Santaella (2003, 2004, 2008) entre outros. O texto se constitui como uma revisão bibliográfica de base teórica. Como resultado, constata-se que o autor e o leitor de fanfiction constituem um público que utiliza da habilidade de multiletramentos e amplia as possibilidades de produção e divulgação de narrativas inerentes a Cibercultura.

Palavras-chave: Cibercultura. Fanfiction. Autor. Escritor.

\section{Narrative of Fanfiction: the author and the reader (un) authorized by cyberculture}

\section{Abstract}

The study, inspired by the assumptions of Cyberculture, addresses the process of authorizing itself as an author and reader of fanfiction. Approaches the writing and reading practices of fanfiction to discuss the displacement of the author's place and the reader of a text in a context of Cyberculture. For this purpose, a discussion with authors such as Chartier (1999, 2001, 2002), Jenkins (2009, 2015), Marcuschi (2008, 2010) and Santaella $(2003,2004,2008)$ among others. The text constitutes a bibliographical review with a theoretical basis. As a result, it is verified that the fanfiction author and reader constitute an audience that uses the ability of 
multi literacies and expands the possibilities of production and dissemination of narratives inherent to Cyberculture.

Keywords: Cyberculture. Fanfiction. Author. Writer.

\section{Narrativas Fanfictons: el autor y el lector (des) autorizados por la cibercultura}

\section{Resumen}

El estudio, inspirado en las bases de la Cibercultura, aborda el proceso de autorizarse como autor e lector de fanfiction. Aborda las prácticas de escritura y lectura de fanfiction para, como desdoblamiento, discutir el dislocamiento del lugar del autor y del lector de un texto en un contexto de Cibercultura. Para eso propondremos una conversa con autores como Chartier (1999, 2001, 2002), Jenkins (2009, 2015), Marcuschi (2008, 2010), Santaella $(2003,2004,2008)$ entre otros. Se constituye como una revisión de bibliográfica de base teórica. Como resultado, se constata que el autor y el lector de fanfiction constituyen un público que se utiliza de la habilidad de literacidad literaria y amplía las posibilidades de producción y divulgación de narrativas inherentes a la Cibercultura.

Palabras claves: Cibercultura. Fanfiction. Autor. Escritor.

\section{A abertura e o início}

Uma retrospectiva da história da Literatura, ainda que de modo breve, parece indicar uma pretensão à universalidade. $\mathrm{O}$ discurso estético que compõe uma obra literária é a matéria prima de análise da crítica em Literatura e baliza a questão canônica da sua qualidade artística. Cânone, etimologicamente falando, vem do latim (canon) que significa regra, padrão, modelo e, por isso, pode assumir o sentido conotativo de sagrado.

O cânone literário se refere, de uma modo geral, a um conjunto de obras avaliadas como possuidoras de um alto valor artístico, portanto consideradas autorizadas, exatas e modelares no âmbito da Literatura. Frente ao princípio da autonomia estética, o acervo de obras literárias canonizadas se torna sagrado, digno de ser estudado e lido por sucessivas gerações. Ao considerar as condições históricas e sociais de cada leitor, a alta Literatura se abre 
às múltiplas interpretações e inferências de quem a decifra, sem, entretanto, abrir mão de sua natureza sagra, canônica.

A partir desse modelo legitimado pela crítica literária, surgem as concepções do que vem a ser Literatura e da atribuição de competência e autorização como autor e leitor de uma obra clássica. Entretanto, a questão canônica que valida uma obra artística e autoriza seu autor insere-se em um campo de discussão e confronto entre duas posições divergentes: de um lado, os que contestam a validade do discurso canônico, entendido como materialização do poder que busca a hegemonia e, do outro lado, àqueles que defendem a manutenção do cânone literário como patrimônio cultural da humanidade.

Nesse interstício, de modo contínuo e destemido, surgem outras formas do fazer literário com novos focos narrativos, novos modos de produção e divulgação que implicam novos processos de autorização de escrita e leitura. Aportados em um contexto de Cibercultura, um movimento de leitores apaixonados pela Literatura deslocam suas escritas da periferia para o centro da discussão literária e inquieta seus cânones consolidados no tempo. São fãs que, em coletividade, passam a discutir, analisar e criticar obras conhecidas, apostos para deslocar de suas posições de leitores/ consumidores passivos para se autorizarem escritores/coautores de obras tidas como originais.

Nasce a fanfiction, recortada aqui, como narrativa produzida por fãs a partir de obras da Literatura e outras mídias. No processo de produção da narrativa, o autor se autoriza a utilizar cenários, personagens e tramas já criadas ou optar pela intertextualidade por utilizar enredos e personagens de diferentes obras originais para compor uma nova história. As histórias se expandem e se aprimoram para se ajustarem aos valores culturais da contemporaneidade. Nesse sentido, se constituem como novas narrativas, onde o discurso estético se configura como arte. Surge uma nova modalidade de discurso literário.

Assim, antigas questões passam a ser acendidas: quem determina o que é Literatura? A quem cabe autorizar o processo de 
escrita de uma Literatura? Qual parte cabe ao leitor no processo de autoria de uma produção que se perpetua com o passar do tempo? Que Literatura se configura em um ambiente volátil, fluido, hipertextual, dinâmico e desterriorializado da Cibercultura?

Nesse contexto de discussão acerca da Literatura se insere esse estudo inspirado nos pressupostos da Cibercultura. Objetivase abordar o processo de autorizar-se enquanto autor e leitor de fanfiction. Defende a tese de que as práticas de produção de fanfiction contribuem para transformar o ato de ler, antes uma prática silenciosa, em uma conversa ativa e dialógica entre escritor, obra e leitor. Ao flexibilizar os lugares de autor/texto/leitor, a fanfiction pode mudar o relacionamento entre os gêneros clássicos da Literatura e a Literatura digital, aproximando dois polos de uma mesma arte em um ponto congruente: refletir sobre realidade.

À vista disso, o texto se define como uma revisão bibliográfica de base teórica. Sua abrangência é temática, porque envolve um recorte transversal sobre a narrativa de Fanfiction na Cibercultura. Entabula-se uma conversa com autores como Chartier (1999, 2001, 2002), Jenkins (2009, 2015), Marcuschi (2008, 2010), Santaella $(2003,2004,2008)$ e outros.

O artigo está organizado em três seções. A primeira trata da Cibercultura e de como se configura o lugar de leitor e de autor nesse contexto de reformulação de práticas de leitura e escrita. A segunda parte aponta a narrativa contemporânea, do gênero digital fanfiction. A última seção, explica como a fanfiction pode redefinir o autor, leitor e o processo de conhecer o mundo como leitor -autor e praticante cultural.

\section{O leitor na Cibercultura}

As formas de ler e escrever se inserem em um contexto de cultura, portanto sofrem modificações com o passar dos tempos e implicam novas posturas leitoras e de autoria. As tecnologias da informação e comunicação, unidas a outras mudanças sociais e culturais contribuem para abrir espaços a diferentes suportes de leitura 
e escrita que transcendem o marco da cultura impressa (CHARTIER,1999).

Os avanços tecnológicos ocorridos a partir da segunda metade do século XX destacam-se pela capacidade de articular pessoas e costumes, de convergir culturas e múltiplas linguagens nas dimensões do oral, da escrita e do digital, e de converter sons, imagens, gráficos e textos em formatos legíveis pelo computador. Ademais, possibilitou emergir um novo paradigma cultural que autores como André Lemos (2002) e Lucia Santaella (2003) chamam de Cibercultura.

Para Lemos (2002, p. 131), a Cibercultura é uma forma “[...] sociocultural que emerge da relação simbiótica entre a sociedade, a cultura e as novas tecnologias de base macroeletrônicas.". Na mesma linha de pensamento, Santaella (2003, p.77) entende que a cultura contemporânea é formada a partir de um complexo de redes em "[...] imbricamento de diferentes lógicas comunicacionais em um mesmo espaço social.”.

As redes digitais formam comunidades virtuais que habitam o ciberespaço e se interligam com as comunidades do espaço físico ao ponto de possibilitar que surja uma nova forma de cultura, a cultura contemporânea com marcante traço cibernético, a Cibercultura. Fato de certo modo previsível, afinal, como adverte Santaella (2003, p. 45-46), “[...] quaisquer meios de comunicação ou mídia são inseparáveis das suas formas de socialização e cultura que são capazes de criar, de modo que o advento de cada novo meio de comunicação traz consigo um ciclo cultural que lhe é próprio.”.

No que refere a Literatura em um contexto de Cibercultura, ela apresenta características onde passado, presente e futuro se imbricam. A tradição das narrativas literárias canônicas ou não, são adicionadas às variadas formas de linguagens contemporâneas e novos modos de escritas individuais e coletivas que, consequentemente, demandam variadas formas de leituras. Ao definir a leitura, Darnton (2010, p. 200) diz que pode-se imaginá-la como “[...] um processo direto de extrair informações de uma página, mas, considerando-a um pouco mais além, concordaríamos que a informação precisa ser 
peneirada, classificada e interpretada." São os esquemas interpretativos utilizados pelo leitor que atribuem à leitura um caráter cultural, pois, como infere Darnton (2010, p. 201), “[...] nossos antepassados em mundos mentais diferentes, deviam ler de maneiras diferentes, e a história da leitura pode ser tão complexa quanto a história do pensamento". Como desdobramento da história da leitura, dois conceitos ligados às narrativas sofrem implicações significativas, o conceito de leitor e seu termo correlacionado, autor.

Para Chartier (2002, p. 113), com a informatização, a contemporaneidade testemunha uma revolução no campo da leitura e escrita com proporções ampliadas ao leitor e ao autor, pois " [...] a revolução do texto eletrônico é, de fato, ao mesmo tempo, uma revolução da técnica de produção do texto, uma revolução do suporte do escrito e uma revolução das práticas de leitura.”. De forma que, o esforço de aproximações entre o lugar do leitor e do autor no mundo moderno e no contemporâneo, implica salientar que eles mudaram com o tempo.

O que parece perene na história da leitura é o sentimento de satisfação ante o escrito e aplicabilidade na vida cotidiana que ela costuma despertar no leitor. Como afirma Chartier (2001, p. 243), “[...] por meio de um livro se pode transformar a visão do mundo social e, através da visão de mundo, transformar também o próprio mundo social.". Nesse quesito, independe da classificação da narrativa diante da crítica literária, afinal, acrescenta Chartier (2001, p. 243), os livros que "[...] celebram o mundo social não são somente os grandes livros proféticos, a Bíblia ou O Capital; há também o doutor Spock, que, do ponto de vista da eficácia simbólica, é, sem dúvida, em sua ordem, tão importante quanto numa outra foi O Capital.".

Tal entendimento contribui para inserir o leitor no centro da discussão sobre narrativas ao passo que lateraliza o suporte textual e o próprio texto. Isso porque para Chartier (1999) a leitura, enquanto produção de significados, será sempre uma apropriação, uma invenção do leitor que desloca e subverte o que o livro lhe pretende impor. Mas, o deslocamento e a subversão 
feita pelo leitor estão, muitas vezes, condicionadas a sua capacidade leitora, as convenções sociais e os hábitos que caracterizam as práticas de leitura.

Participativo e com maiores possibilidades de leituras. Conforme Santaella (2004), o leitor do livro passou a ser o mesmo da imagem e este ao leitor das formas híbridas de signos e processos de linguagem, incluindo nessas formas até mesmo o leitor da cidade e o espectador de cinema, TV e vídeo. A diversidade de situações de leitura que o contexto cultural apresenta cobra habilidades sensoriais e perceptivas que configuram modelos cognitivos de leitores.

Disso resultaram, para Santaella (2004) três tipos de leitores: o leitor contemplativo, o leitor movente e o leitor imersivo. Eles possuem perfis cognitivos que marcam a sociedade a partir do Renascimento. Embasado na autora, intenta-se descrever estes leitores e assim entender como o leitor na Cibercultura age e interage.

O primeiro é o leitor contemplativo, meditativo. Emerge em uma sociedade pré-industrial, entre o Renascimento até meados do século XIX. É o leitor do livro impresso e da imagem expositiva, fixa. Segundo Chartier (1999, p. 23), com a instauração obrigatória do silêncio nas bibliotecas, a leitura passou a estar relacionada ao olho e "[...] não mais acompanhada, como antes, pelos rumores de uma articulação vocal, nem pelo movimento de manducação muscular.".

Santaella (2004, p. 24) descreve o leitor contemplativo como “[...] aquele que tem diante de si objetos e signos duráveis, imóveis, localizáveis mensuráveis: livros, pinturas, gravuras, mapas, partituras. [...] Esse leitor não sofre, não é acossado pela urgência do tempo.". Para a autora, na interação com o texto "a visão reina soberana, complementada pelo sentido interior da imaginação.” A capacidade imaginativa do leitor torna a sua atividade leitora produtiva, pois todo ato de ler envolve "[...] inferência, julgamento, memória, reconhecimento, conhecimento, experiência e prática.” (MONGUEL, 1997, p. 54). 
O segundo leitor é o movente, fragmentado que está inserido no mundo heterogêneo, contemporâneo da Revolução Industrial. Vivencia a consolidação do jornal, cinema, fotografia e alcança o surgimento da televisão. Filho da Revolução Industrial que vive e convive em uma situação citadina, em movimento, em mistura de signos. Na classificação de Santaella (2004, p. 30), o leitor de livros, observador, possuidor de faculdades imaginativas férteis se reconfigura em um "[...] leitor de formas, volumes, massas, interações de forças, movimentos; leitor de direções, traços, cores, leitor de luzes que se acendem e se apagam [...]". Para a autora, o segundo tipo de leitor insere-se na fronteira entre o leitor contemplativo e um leitor que despontará em uma cultura ciber, o leitor imersivo.

Finalmente, para Santaella (2004, p. 31), emerge o terceiro perfil de leitor que navega em "[...] conexões alineares pelas arquiteturas líquidas dos espaços virtuais”. É o leitor imersivo, virtual, que inaugura a entrada do século XXI. Trata-se de um perfil de leitor que atua no âmbito da virtualidade. É o leitor imersivo que a autora define por ser um leitor que emerge em novos espaços virtuais. Este hibridiza a parcialidade com a hiper parcialidade dos incomensuráveis textos que estão entremeados nas teias da Cibercultura. Segundo a autora, sua principal característica é a interatividade e, sobretudo, as mudanças sensoriais, perceptivas e cognitivas que este novo modo de ler revela nesta nova cultura. A nova configuração do leitor imersivo permanecerá e continuará em constante evolução. Evolução cognitiva, sinestésica e semiótica.

Apesar de categorizá-los e vê-los de forma mais profunda Santaella (2004, p. 19,20) reitera que:

[...] embora haja uma sequencialidade histórica no aparecimento de cada um desses tipos de leitores, isso não significa que um exclui o outro, que o aparecimento de um tipo de leitor leva ao desaparecimento do tipo anterior. [...] O que existe, assim, é uma convivência e reciprocidade entre os três tipos de leitores,embora cada tipo continue, de fato, sendo irredutível ao outro, exigindo, aliás, habilidades perceptivas, sensório-motoras e cognitivas distintas. 
O que percebe-se, assim, é uma evolução do leitor. Esta evolução está entendida aqui como um movimento contínuo e harmonioso acompanhando as novas formas de comunicação e de difusão do texto escrito. Há portanto, uma acumulação de habilidades que podem ser selecionadas segundo a conveniência do leitor.

No plano da linguagem, todo texto nasce de relações dinâmicas com outros textos oriundos de lugares, épocas e contextos diferenciados. O que equivale dizer que todo texto é uma composição de relações linguísticas, históricas, sociais e culturais amalgamadas em uma composição textual onde o autor cumpre uma função de representante do momento histórico em que vive.

Para Chartier (1999, p. 17) os “[...] autores não escrevem livros: não, eles escrevem textos que se tornam objetos escritos, manuscritos, gravados, impressos e, hoje, informatizados." Aceitar o deslocamento do lugar de autor implica aceitar o leitor e sua mediação com o texto de uma forma diferenciada. Cada leitura, diante das relações interna e externas do texto, torna o leitor um coautor na medida que o texto se abre à leitura e significação diante do leitor. Portanto, autor e leitor fazem parte de uma rede de relações que se dá a partir da linguagem em suas variadas formas, inclusive, narrativas. Ao se utilizar o suporte tecnológico, as novas narrativas ficcionais integram

[...] texto escrito, imagem, som e narração oral, narração imagética, linguagem-jogo e tudo de maneira simultânea na construção de narrativa ficcional com certo grau de interatividade direta. As opções são diversas, e cabe a quem escreve escolher qual o melhor recurso compositivo a ser gerado em prol do impacto almejado tendo em vista obter um efeito específico pelo leitor/leitor-escritor (MENESES, 2009, p. 69)

As novas formas de narratividade parecem não negar a estrutura basilar da narrativa canônica composta de espacialidade, temporalidade e sujeito, interligados em uma relação de causa e feito, mas avançou para uma estrutura narrativa "sustentada pela linguagem articulada, oral ou escrita, pela imagem, fixa ou móvel, pelo gesto ou 
pela mistura ordenada de todas essas substâncias" como afirma Barthes (2008, p. 19). Dessa forma, a noção de textualidade sofre algumas alterações, pois a narrativa ficcional na cibercultura se constitui num texto plural, sem centro discursivo, sem margens, sendo produzido por um ou vários autores, sempre em mutação e reconstrução, de forma associativa, cumulativa, multilinear e instável.

Novas formas de ler também resultam em novas formas de escrever. A Cibercultura e as leis que a regem convertem os leitores em produtores. Sobre uma das formas de ler e escrever na Cibercultura é que trataremos no tópico a seguir. Abordaremos sobre as fanfiction como resultado da ação e reação dos leitores na Cibercultura.

\section{Fanfiction: A nova forma de (re)ler e (re)escrever}

A partir de uma analogia com a arte, a fanfiction se configura como uma releitura, criada a partir de uma apropriação e que cita os elementos de suas referências. Este tipo de releitura implica em reler, mas não somente, implica em atribuir um novo sentido. $\mathrm{Na}$ Cibercultura apropriar-se é algo recorrente assim como citar e mencionar outras obras nas diversas plataformas. Segundo Jenkins (2009), a fanfiction representa um exemplo vívido da ação de ler criativamente e criticamente; convertendo-se assim em uma nova forma de ler e escrever na Cultura Digital.

Fanfiction ipsi litteris significa Ficção de Fã. Os novos consumidores ativos, não mais meros espectadores, são criadores; e como fãs e profundos conhecedores do que consomem, estão aptos a expandir sua série, filme, livro etc. de acordo com seus próprios interesses e gostos. O universo das fics é tão imenso que algumas fics percorrem o caminho inverso, fazem tanto sucesso que são publicadas em livros impressos.

As fics como também são chamadas as fanfictions, não surgiram do nada e não se tornaram um fenômeno repentinamente. O precursor das fanfictions foram os fanzines. Embora os fanzines tenham surgido na década de 1930 com publicações de ficção científica o termo fanzine foi adotado em 1941 por Russ Chauvenet. O termo 
descende das palavras em inglês fanatic (fã) e magazine (revista). Os fanzines, portanto, são narrativas alternativas escritas por fãs ou grupos de pessoas sobre algo de interesse comum aos envolvidos.

Entende-se, assim, que o conceito de fanfiction e fanzine é totalmente convergente; no entanto o que diferencia um do outro é o local onde estes são publicados. Os fanzines eram publicações impressas artesanalmente e de pouca impressão. Já as fanfictions são narrativas escritas e publicadas no meio digital e que pode atingir um número inimaginável de pessoas ao redor do mundo.

Outro ponto de confluência entre o fanzine e a fanfiction é que, ambos, são narrativas escritas por "amadores" que consomem algum livro, filme ou série e a partir desta, constroem narrativas alternativas inspiradas no que foi consumido. Estas estão, portanto, inseridas no meio das narrativas transmidiáticas.

As narrativas transmidiáticas são histórias que se desenrolam em múltiplos dispositivos de mídia. Esta itinerância proporciona múltiplas visões de um mesmo produto. No entanto apesar de discorrer sobre o mesmo tema tais narrativas são independentes, porém com a mesma trama. Por meio destas narrativas que, circulam nas diversas mídias percebemos o poder do fã e do universo o qual ele faz parte. Jenkins (2009, p.138) ratifica:

Uma história transmídia desenrola-se através de múltiplas plataformas de mídia, com cada novo texto atribuindo de maneira distinta e valiosa para o todo. Na forma ideal de narrativa transmídia, cada meio faz o que faz de melhor - a fim de que uma história possa ser introduzida num filme, ser expandida pela televisão, romances e quadrinhos; seu universo possa ser explorado em games ou experimentado como atração de parque de diversões. Cada acesso à franquia deve ser autônomo, para que não seja necessário ver o filme para gostar do game, e vice-versa.

O ciberespaço proporciona, na Cibercultura, um lugar de fluxo de intercâmbios entre escritores, ou como Jenkins (2015) denomina invasores do texto. Apesar o termo "invasor" soar pejorativo, no contexto da Cibercultura, regida por três fortes princípios 
de: liberação do polo de emissão, conexão planetária e reconfiguração, tal termo legitima a natureza da fanfiction. Os escritores de fanfiction são, logo, validados pelos princípios da Cibercultura e os põem em prática dentro dos seus universos criados para compartilhar as suas perspectivas a respeito do que consomem. Jenkins (2015, p. 22) define a media fandom por:

É um grupo que não adota um texto único nem um gênero singular, mas textos diversos - seriados dramáticos norte-americanos e britânicos, filmes hollywoodianos de gênero , quadrinhos, animação japonesa, ficção popularesca (em especial ficção científica, fantasia e suspense) - e ao mesmo tempo, ergue barreiras que costumam excluir outras variedades de textos (com destaque para telenovelas e a maior parte dos livrinhos românticos).

O leitor/escritor libera sua criação através da World Wide Web que conecta usuários de todo o mundo. Estes compartilham os mesmos interesses e reconfiguram, remixam e recriam suas próprias histórias transformando a fanfiction em um gênero textual digital que se expande no ciberespaço. Trata-se da cultura da participação, cultura esta, onde o indivíduo compartilha, toma parte e faz-se saber. Esta cultura fomenta a colaboração, redefine as formas de recepção de conteúdo, as comunidades e o papel do indivíduo na sociedade e articula novas práticas culturais, intermediadas pelo digital em rede.

As mudanças no ato de ler e escrever mudaram com a Cibercultura, assim a prática de leitura e escrita na Cibercultura ocorre por meio de novas experiências de multiletramentos, aqui entendido como letramentos inseridos em uma sociedade que vivencia o enraizamento das Tecnologias Digitais da Informação e Comunicação. Estas tecnologias associadas à web 2.0 trazem consigo a possibilidade de que cada um de nós, além de consumir textos, possamos produzi-los e publicá-los convertendo-nos, no Rojo (2015) denomina de, lautor.

Ler e escrever fics são ações inseparáveis. Alguns leitores e escritores de fanfiction o fazem por prazer e por se sentirem enga- 
jados e impulsionados à fazê-lo por sua paixão ao texto original. A leitura dentro deste contexto abarca várias modalidades: visual, informática, multicultural e crítica. A construção do letramento digital deve envolver uma consciência sistemática de como são construídos os meios digitais e da retórica única da comunicação interativa: no caso da internet e das tecnologias digitais, por exemplo. O foco do tópico a seguir será justamente sobre como a leitura e a escrita deste gênero textual digital redefine o que conhecemos por leitor e autor na Cibercultura.

\section{A escrita da fantiction: um novo gênero textual digital}

O gênero digital fanfiction é um fenômeno em expansão na Cibercultura. Especialmente, pelas possibilidades criadas através da popularização dos variados ambientes virtuais, tais como sites especializados em agrupar estas narrativas digitais por categorias, comunidades virtuais dos fãs de ficção, por reino de ficção (fandom), em blogs especializados de personagem, cosplay, redes sociais digitais, entre outros.

No que se refere ao surgimento de novos gêneros discursivos adaptados aos ambientes digital online. À vista disso, entendemos os gêneros textuais entremeado pelo digital como produções que se adaptam e ganham novos sentidos e significados. É o que fica ratificado nas considerações de Bakhtin (2003) e Marcuschi (2010) sobre os gêneros discursivos que ganham novos papéis de acordo com a circulação nos espaços virtuais.

Antes de aprofundar-se em fanfiction enquanto gênero textual na Cibercultura, mas sobretudo como a concretização do novo leitor e autor nesta cultura; faz-se necessário entender o conceito de gênero textual e suas implicações. Segundo Marcuschi (2008, p. 149) gênero refere-se à uma categoria distinta de discurso, seja falado ou escrito. Os gêneros estão presentes em nosso dia a dia e fazemos uso deles nas mais diversas situações. $\mathrm{O}$ autor afirma que: 
O trato dos gêneros diz respeito ao trato da língua em seu cotidiano nas mais diversas formas. E se adotarmos a posição de Carolyn Miller (1984), podemos dizer que os gêneros são uma “ forma de ação social". Eles são um "artefato cultural" importante como parte da estrutura comunicativa de nossa sociedade.

Por outro lado, os tipos textuais são a narração, argumentação, exposição descrição, injunção; estes são mais restritos e, segundo Marcuschi (2008) não tendem a aumentar. Logo, os gêneros textuais estão inseridos em tipos textuais, sendo possível reconhecê -los a partir de características do tipo textual.

Os tipos textuais inseridos na sociedade, no contexto da Cibercultura (re)produzem novos gêneros textuais. Para Bakhtin (2003) a língua, enunciado e os gêneros do discurso se conectam para que haja uma comunicação eficiente. Por isso, as relações humanas reconfiguram os gêneros textuais todo o tempo, uma vez que estão circulando no meio social.

É possível perceber que diante da fluidez dos gêneros textuais e discursivos e sob a influência da cultura digital, há uma emersão de novos gêneros textuais no ciberespaço. Alguns recebem mais prestígio, outros nem tanto; o que se deve considerar é que a Cibercultura reconfigura a dinâmica de gêneros textuais, dando espaço a novos e adaptando os antigos. Aqui entenderemos como isto se reconfigurou ampliando a discussão para as fanfictions como um gênero textual.

As características da construção das fanfiction na qualidade de gênero digital perpassam por etapas diferentes de apropriação da produção “original”. Pela leitura, e reconfiguração ou expansão dos sujeitos sociais, pelo engajamento dos fãs de ficção em rede a partir da convergência midiática. Essa convivência com as mídias e o diálogo tem relação com a cultura da convergência midiática (conceito basilar fundamentado por Jenkins (2009), o que, adiante, eleva o terreno do efeito transmidiático dos conteúdos comunicacionais).

Diante dessas características, esses sujeitos, fãs de ficção começam a elaborar a produção de narrativas ficcionais, (inspiradas 
em uma produção original), então por sua vez, as relações de como interagir, manipular, continuar, elaborar e apropriar-se do conteúdo ficcional também estabelecem novas maneiras e estratégias de agir, consumir e construir narrativas ficcionais a partir das práticas sociais e discursivas que fluem, especialmente neste contexto da Cibercultura.

O gênero textual fanfiction entendido como gênero digital ou vice-versa, caracteriza um ambiente de produção textual e autoria, práticas de convergências que são próprios da Cibercultura. Esta autoria e práticas são elaboradas por sujeitos independentes ou não, possibilitando que neste recorte da cultura digital exista mais observação e investigação sobre as interações sociais e discursivas dos fãs de ficção.

Para tanto, esse formato de narrativas ficcionais elaborados por fãs de ficção propõe não somente continuidade à narrativa original. Elas agregam novas atribuições aos personagens e desdobramentos alternativos, criticamente, pensados por sujeitos sociais não conformados com a recepção passiva, mas, em rede são empoderados a constituírem uma cultura digital coerente, mas reconfigurada, organizada e diferenciada mediante a estrutura dos espaços virtuais. E, ainda, das interações possíveis para encontrar pares dispostos a congregar do mesmo ideário em rede.

À vista disso, as práticas de convergência ou participação possibilitam a aprendizagem e o letramento por meio das expansão de narrativas com linguagem digital. Essas narrativas ficcionais movimentam as interações dos leitores/fãs de ficção imersos no universo elaborado, construído e compartilhado por esses mesmos sujeitos sociais coletivamente nas redes online na Internet. Tais características possibilitam um cenário favorável ao desenvolvimento de habilidades de leitura e escrita e consequentemente a medicação da aprendizagem a partir da apropriação de uma nova língua, e consequentemente do domínio da linguagem digital na perspectiva pedagógica. 


\section{No limite do texto: cortemos o fio}

Eleger a fanfiction como objeto de estudo implica assumir o compromisso de abordar a função do leitor e do autor de narrativas e suas possíveis aproximações e permutas no processo de produção da obra. O nascimento de uma narrativa de fanficion está vinculado a uma leitura apaixonada de uma obra literária, no caso recortado nesse estudo, a partir da perspectiva do leitor e da sua interação com a narrativa.

Portanto, se tornar autor de fanfiction implica percorrer etapas de revisão, adaptação e elaboração diferenciada da narrativa a parir dos elementos identificados na obra original. Esse trabalho tem despertado a atenção e dividido opiniões quanto a sua legitimidade e originalidade. De fato, a postura de resistência ao uso desautorizado de obras autorais parece se contrapor a postura de defesa da liberdade de expressão e criação. Entretanto, um ponto de vista contemporâneo admite a existência de antagonismos como marcas de uma sociedade múltipla, fluída, onde se imbricam formas tradicionais de produção e formas descentralizadas de narrativas.

O advento das tecnologias possibilitou mudanças no comportamento do homem, um ser cultural, que afetou suas formas de escrita e leitura: a técnica de produção multimidiática implica uma obra reeditada em coautoria. Assim, a Cibercultura não só modificou o processo de leitura e escrita, como também autorizou o leitor a se permutar com o autor na criação de inúmeras versões de uma mesma obra literária. Como consequência, testemunha-se o surgimento de comunidades de fãs que transmutam do lugar de leitores contemplativos e moventes para o lugar de leitores sujeitos efetivamente ativos e imersivos.

Assim, a sociedade contemporânea, com fortes marcas de cultura ciber, possibilita maior participação do leitor, como tantos escritores têm desejado há muito tempo, que evade do lugar de leitor passivo e passa a ocupar um lugar de leitor ativo, que interfere, dialoga e acrescenta ao texto pronto e canônico. Entende-se a ficfiction como consequência da Cibercultura que apresenta um palco 
onde o jovem escritor/autor pode se apresentar enquanto sujeito crítico/pensante, além de exercitar diversas habilidades relacionadas à leitura como pensamento crítico e construção de significados.

Consequentemente, constata-se que o autor e o leitor de fanfiction constituem um público que utiliza da habilidade de letramento literário desenvolvido e impulsionado pela leitura de obras canônicas e amplia as possibilidades de produção e divulgação de narrativas em um contexto de autorização advindo da Cibercultura.

\section{Referências}

BAKHTIN, M. Os gêneros do discurso. In: BAKHTIN, M. Estética da criação verbal. Tradução: Paulo Bezerra. São Paulo: Martins Fontes, 2003. p. 261-306.

BARTHES, Ronald. Analise estrutural da narrativa. Tradução: Mário Laranjeira. 5. ed. Petrópolis: Vozes, 2008.

CHARTIER, Roger. A Aventura do livro: do leitor ao navegador. Tradução: Reginaldo Carmello Corrêa de Moraes. São Paulo: Editora UNESP, 1999.

CHARTIER, Roger. Cultura escrita, literatura e história; conversas de Roger Chartier com Carlos Aguirre Anaya, Jesus Anaya, Daniel Goldin e Antônio Saborit. Porto Alegre: Artmed editora, 2001.

CHARTIER, Roger. O desafio da escrita. Tradução de Fluvia M. L. Maretto. São Paulo: editora UNESP, 2002.

DARNTON, Robert. A questão dos livros: passado, presente e futuro. Tradução: Daniel Pellizzari.São Paulo: Companhia das letras, 2010.

JENKINS. Henry. Invasores do texto: fãs e cultura participativa. Tradução Érico Assis. Nova Igauçu: Marsupial, 2015

JENKINS, H. Cultura da convergência. Tradução: Suzana Alexandria.2. ed.São Paulo: Aleph, 2009. 432p.

LEMOS, André. Cibercultura: tecnologia e vida social na cultura contemporânea. Porto Alegre: Sulina, 2002.

MARCUSCHI, Luiz Antônio. Gêneros textuais emergentes no contexto da tecnologia digital. In: MARCUSCHI, Luiz Antônio; XAVIER, Antônio Carlos. (Org). Hipertexto e gêneros digitais: novas formas de construção de sentido. 3. ed. São Paulo: Cortez Editora, 2010. 
MARCUSCHI, Luiz Antônio. Produção textual, análise de gêneros e compreensão. São Paulo: Parábola Editorial, 2008.

MANGUEL, Alberto. Uma história da leitura. São Paulo: Companhia das Letras, 1997.

MENESES, Salon Silva. Cibernarratologia: um estudo integrado sobre narrativas na cibercultura. Tese (Doutorado em Teoria literária e Literatura) - Universidade de Brasília, Brasília, 2009.

ROJO. Roxane H. R. Hipermodernidade, multiletramento e gêneros discursivos. São Paulo: Parábola, 2015.

SANTAELLA, Lucia. Culturas e artes do pós-humano: da cultura das mídias à Cibercultura. São Paulo: Paulus, 2003.

SANTAELLA, Lucia. Navegar no Ciberespaço: O perfil cognitivo do leitor imersivo. São Paulo: Paulus, 2004.

SANTAELLA, Lúcia. O novo estatuto do texto nos ambientes de hipermídia. In: SIGNORINI, Inês et al (Org.). [Re]discutir texto, gênero e discurso. São Paulo: Parábola Editorial, 2008. p. 47-72.

\section{VERÔNICA ALVES DOS SANTOS CONCEIÇÃO}

Lattes:http://lattes.cnpq.br/5557132314770190 Orcid:https://orcid.org/00000002-5481-0522

E-mail: veronica.alves604@gmail.com Telefone: (79) 99603-6364 (75) 98803-8583

Rua Heracliton Rollemberg, 3400. Cond. Grand Belize, Bloco Kaio, aptº1301, Farolândia - Aracaju-SE CEP 49030-640.

\section{CRISTIANE DE MAGALHÃES (UNIT / ITP-SE)}

Bolsista de Produtividade CNPq Nível 2

Lattes: http://lattes.cnpq.br/3435445286863278 Orcid: http://orcid.org 00000001-5622-030X

E-mail: crismporto@gmail.com telefone: (79) 99180-6084

Rua Profa. Ofenísia Freire - 55 - Cond. Belas Artes - Bloco A. Cruz, ap. 204, Farolândia- Aracaju-SE CEP 49039-213

\section{ISABELLA SILVA DOS SANTOS ( UNIT / SEED-SE)}

CV Lattes: http://lattes.cnpq.br/0165503962025785 Orcid:https://orcid.org/0000-0003-2549-904X

E-mail: profeisabellaufs@gmail.com telefone: (79) 9 9960-7841

Rua Rosalina, 120 - Condomínio Via Farol. Edf. Farol de Aracaju, ap. 801, Farolândia- Aracaju-SE CEP 49032-150 